\title{
Bone Mineral Density in Human Immunodeficiency Virus-1 InfeCted Men with Hypogonadism Prior to HighLY-ACTIVE-ANTIRETROVIRAL-THERAPY (HAART)
}

\author{
J. Teichmann ${ }^{1,2}$, U. Lange ${ }^{2}$, T. Discher ${ }^{3}$, J. Lohmeyer ${ }^{3}$, H. Stracke ${ }^{2}$, R. G. Bretzel ${ }^{2}$ \\ ${ }^{1}$ Department of Internal Medicine, Medical Clinic C, Ludwigshafen, Germany \\ ${ }^{2}$ III. Medical Clinic, University of Giessen, Germany \\ ${ }^{3}$ II. Medical Clinic, University of Giessen, Germany
}

\begin{abstract}
Alterations of bone metabolism have been observed in numerous studies of HIV-infected patients. Sex steroids are known to profoundly influence bone mass and bone turnover. Hypogonadism is common in HIV-infection. Therefore, we performed a cross sectional study of 80 male HIV-infected patients without wasting syndrome, and 20 healthy male controls, in whom we analyzed urine and serum samples for both calciotropic hormones and markers of bone metabolism and of endocrine testicular function. Bone mineral density (BMD) was assessed by dual-energy X-ray absorptiometry both in the lumbar spine and Ward's triangle of the left hip. None of the patients received highly-active-antiretroviral-therapy (HAART). Compared to eugonadal HIV-infected patients, subjects with hypogonadism ( $\mathrm{n}=32 ; 40 \%$ ) showed statistically significant decrease of serum osteocalcin $(p<0.05)$ and elevated urinary excretion of crosslinks $(p<0.05)$. However, we found 13 and 15, respectively, patients with osteopenia (t-score -1.0 to -2.5 SD below normal) of the lumbar spine. The dissociation between bone formation and resorption and the reduction of of BMD $(p<0.05)$ is stronger expressed in patients with hypogonadism. Habitual hypogonadism appears to be of additional relevance for bone metabolism of male HIV-positive patients prior to HAART.
\end{abstract}

Key words: HIV, Hypogonadism, Bone Mineral Density, Calciotropic Hormones

\section{INTRODUCTIONS}

Alterations of bone metabolism have been observed in numerous studies of small groups of male patients infected with HIV. Both hypocalcemic [1, 2] or hypercalcemic phases $[3,4,5,6]$ reduced serum osteocalcin levels $[7,8,9]$ and hypoparathyroidism $[5,7,9]$ have been reported. The reduction of bone mineral density (BMD) has been observed in several studies of HIVafflicted patients $[10,11,12,13]$. Testosterone deficiency is a risk factor for osteoporosis in male and female patients $[14,15,16]$. Sex hormone deficiency is among the most frequent endocrine abnormalities in HIV-1 infected men, and it's clinical symptoms (impo- tence and decreased libido) have been reported in 33 and $67 \%$, respectively [17]. Based on the theory that sex hormone deficiency is mediated through direct osteoblastic and osteoclastic effects, modulation of cytokine milieu, and extraskeletal effects on calcium homeostasis [2], we performed a cross sectional study of $80 \mathrm{HIV}-1$ infected male subjects, in whom we assessed both biochemical markers of bone metabolism and BMD by dual-energy X-ray absorptiometry (DEXA). Thus, the aim of this investigation was to examine the prevalence of hypogonadism in the HIVinfected outpatients, and to determine the alterations of bone metabolism in HIV-infected patients with hypogonadism compared to those with eugonadism and the manifestation of osteopenia in these patients.

\section{PATIENTS}

80 male patients with a recently confirmed serodiagnosis (including Western blot analysis) of HIV-1 infection participated in the study. They were examined in our outpatient clinic (age range 23 to 45 years). At the time of examination the patients had no concomitant opportunistic infections; no acute or chronic hepatitis with increased liver transaminase activities; nor alterations of the liver parenchyma under sonomorphological criteria; no wasting symptoms; no gastrointestinal disorders such as pancreatic insufficiency or malabsorption syndrome nor chronic diarrhea. The patients did not take any drugs known to influence the characteristics of bone metabolism or the endocrine system, Patients did not receive antiretroviral like protease inhibitors or reverse trancriptase inhibitors for additional antiretroviral therapy.. Patients with cytomegaly-associated chorioretinitis were excluded from the study, since treatment with Foscarnet or Gangciclovir is known to affect the serum calcium level $[18,19]$. Clinical data are shown in Table 1. Fasting blood samples were obtained by puncture of a cubital vein. The serum was frozen and stored at $-30^{\circ} \mathrm{C}$. 24-h urine samples were collected after a gelatin-free diet for 24 hoursand stored without additives at $-30^{\circ} \mathrm{C}$. An agematched control group consisting of 20 healthy individuals ( 20 males, group III) was studied for comparison. No inividual performed extreme physical exercise. 


\section{Methods}

The lymphocyte subpopulations (CD4) were determined using monoclonal fluorescent antibodies and the FACscan autoanalyzer (both from Becton-Dickinson). Total pyridinolines were measured using a RIA kit from Biermann, Bad Nauheim, Germany. The reference value for this kit was set at values lower than 50 $\mathrm{nmol} / \mathrm{pyd} / \mathrm{nmol}$ creatinine. Serum calcium, phosphate, creatinine and albumin as well as the urinary excretion of calcium, phosphate, and creatinine were measured by standardized laboratory methods. Plasma PTH (1-84) was determined by radioimmunoassay (RIA) from the Nichols Institutes, Wijchen, The Netherlands. Serum osteocalcin was measured using a commercial RIA kit from Incestar, Stillwater, Minnesota, USA. The inter- and intra-assay coefficients of variation were $5 \%$ and $10 \%$, respectively (reference 2,0 to $6,5 \mathrm{pg} / \mathrm{ml})$. Calcitonin was measured using a RIA kit from Biermann, Bad Nauheim, Germany (normal values $5-15 \mathrm{pg} / \mathrm{ml}$ ). Vitamin D concentration: 1,25-dihydroxycholecalciferol $(1,25(\mathrm{OH}) 2 \mathrm{D} 3)$ in serum was determined using a RIA from Nichols Diagnostics, Wijchen, The Netherlands (detection limit 5,0 ng/ml); $25(\mathrm{OH}) \mathrm{D} 3$ was determined using a RIA from Nichols Diagnostics, Wijchen, The Netherlands (normal values $8-80 \mathrm{ng} / \mathrm{ml}$ ). The marker of the gonadal axis were measured by means of commercially available kits: FSH and LH RIA, (Biermann, Germany); prolactin and total testosterone RIA, (BYK, Germany).

\section{BMD MEASUREMENTS}

The measurement of the bone mineral density (BMD) was performed using dual-energy X-ray absorptiometry (DEXA) of the LUNAR Radiation Corporation, Madison, Wisconsin, United States. Measurements were taken at the lumbar spine (L1 to L4 a.p.) and Ward's triangle of the left hip. Low BMD was defined according to World Health Organization (WHO) guidelines as a T-score less than -2.5 SD below the mean of young healthy adults.

\section{STATISTICAL ANALYSIS}

Normal distribution of data was analyzed by the Kolmogorow-Smirnov normality test.The mean values of the different groups and their standard deviations were compared by means of Student's t-test. Differences of $\mathrm{p}<0,05$ were considered statistically significant. Data, that showed unequal variance or abnormal distribution, were analyzed by Mann-Whitney rank sum test. Statistical analysis was performed using Statistical Package for Social Science (SPSS) [20].

\section{RESULTS}

Age, CD4-cell-count, weight, body mass index, and the drug treatment are shown in Table 1. with means \pm standard deviation of the respective groups. Weight and body mass index were found to be significantly lower in the two groups of male HIV-1infected patients as compared to the control group.

Serum total testosterone was significantly decreased below the normal range in $32(40 \%)$ male patients (group I). Group II comprised the 48 male HIV-1 infected subjects with normal testosterone levels. Their individual FSH, LH and prolactin levels were within the normal range. The LH and FSH levels of hypogonadal patients ranged near the lower limit and were significantly decreased compared to the levels of eugonadal patients. (Statistical analysis did not show significant differences of the steroid markers between the homosexually or heterosexually active males in the

Table 1. Biochemical markers and characteristics (mean $\pm \mathrm{SD}$ ) of the male HIV-1 infected subjects with hypogonadism (group I); HIV-1 infected male eugonadal patients and healthy controls (significance between HIV-1 infected men of group I or II and controls $* \mathrm{p}<0.05)$ (significance between hypogonadal and eugonadal patients \# $\mathrm{p}<0.05$ ).

\begin{tabular}{|c|c|c|c|c|}
\hline Parameter & $\begin{array}{l}\text { Group I } \\
(\mathrm{n}=32) \\
\text { HIV-1 } \\
\text { hypogonadism }\end{array}$ & $\begin{array}{l}\text { Group II } \\
(\mathrm{n}=48) \\
\text { HIV-1 } \\
\text { eugonadism }\end{array}$ & $\begin{array}{l}\text { Group III } \\
(\mathrm{n}=20) \\
\text { Male, control }\end{array}$ & Range \\
\hline Weight [kg] & $71.4 \pm 4.2 *$ & $74.7 \pm 3.6$ & $78.5 \pm 4.7$ & \\
\hline Body mass index $\left[\mathrm{kg} / \mathrm{m}^{2}\right]$ & $24.1 \pm 2.2$ & $24.9 \pm 3.1$ & $26.05 \pm 5.5$ & \\
\hline Age $[y r]$ & $39.1 \pm 7.2$ & $35.2 \pm 4.3$ & $35.4 \pm 4.1$ & \\
\hline Smoker [total] & 10 & 30 & 5 & \\
\hline Unemployed [total] & 8 & 15 & 0 & \\
\hline Heroin addict & 4 & 0 & 0 & \\
\hline Cotrim [total] & 15 & 23 & 0 & \\
\hline Tuberculostatica [total] & 1 & 2 & 0 & \\
\hline CD4 cell count [total] & $153.5 \pm 56.2 * \#$ & $235.5 \pm 37.5 *$ & $890.0 \pm 69.1$ & 610-970 [total] \\
\hline Prolactin $[\mathrm{mIU} / \mathrm{ml}]$ & $31.1 \pm 3.7$ & $27.4 \pm 2.05$ & $30.8 \pm 5.3$ & $20-50 \mathrm{mIU} / \mathrm{ml}]$ \\
\hline $\mathrm{FSH}[\mathrm{mIU} / \mathrm{ml}]$ & $2.15 \pm 1.4$ *\# & $4.2 \pm 3.1$ & $3.6 \pm 2.6$ & $2.2-19.6[\mathrm{mIU} / \mathrm{ml}]$ \\
\hline $\mathrm{LH}[\mathrm{mIU} / \mathrm{ml}]$ & $1.9 \pm 2.5 * \#$ & $3.2 \pm 2.2$ & $3.2 \pm 1.4$ & $2.5-99.5[\mathrm{mIU} / \mathrm{ml}]$ \\
\hline Testosterone total [ng/dl] & $149.2 \pm 62.5$ *\# & $601.0 \pm 73.2$ & $534.4 \pm 45.8$ & $300-1000[\mathrm{ng} / \mathrm{dl}]$ \\
\hline
\end{tabular}


Table 2. Biochemical markers and characteristics (mean $\pm \mathrm{SD}$ ) of bone metabolism of the male HIV-1 infected patients with hypogonadism (group I); ( significance between HIV-1infected men of group I or II and controls * $\mathrm{p}<0.05$ ) (significance between hypogonadal and eugonadal patients \# $\mathrm{p}<0.05)$.

\begin{tabular}{|c|c|c|c|c|}
\hline Parameter & $\begin{array}{l}\text { Group I } \\
(\mathrm{n}=32) \\
\text { HIV-1 } \\
\text { Hypogonadism }\end{array}$ & $\begin{array}{l}\text { Group II } \\
(\mathrm{n}=48) \\
\text { HIV-1 } \\
\text { Eugonadism }\end{array}$ & $\begin{array}{l}\text { Group III } \\
(\mathrm{n}=20) \\
\text { male controls }\end{array}$ & Range \\
\hline Serum Ca $[\mathrm{mmol} / \mathrm{l}]$ & $2.10 \pm 0.107 *$ & $2.21 \pm 0.1$ & $2.6 \pm 0.23$ & $2.20-2.65[\mathrm{mmol} / \mathrm{l}]$ \\
\hline Serum D 1,25(OH2)D [pg/ml] & $27.9 \pm 9.7 *$ & $31.5 \pm 7.5 *$ & $67.45 \pm 4.25$ & $44-74[\mathrm{pg} / \mathrm{ml}]$ \\
\hline Serum D 25(OH)D $[\mathrm{ng} / \mathrm{ml}]$ & $24.3 \pm 10.3 * \#$ & $46.7 \pm 14.1 *$ & $69.5 \pm 13.5$ & $8-80[\mathrm{ng} / \mathrm{ml}]$ \\
\hline PTH $[\mathrm{pg} / \mathrm{ml}]$ & $19.6 \pm 8.9 *$ & $28.5 \pm 5.2 *$ & $37.8 \pm 4.8$ & $10-65[\mathrm{pg} / \mathrm{ml}]$ \\
\hline Osteocalcin $[\mathrm{ng} / \mathrm{ml}]$ & $2.35 \pm 0.57 * \#$ & $3.58 \pm 0.53$ & $3.6 \pm 0.39$ & $2.0-6.5[\mathrm{ng} / \mathrm{ml}]$ \\
\hline Creatinine $[\mathrm{mg} / \mathrm{dl}]$ & $0.89 \pm 0.1$ & $0.99 \pm 0.14$ & $0.87 \pm 0.15$ & $0.68-1.09 \mathrm{mg} / \mathrm{dl}$ \\
\hline Albumine $[\mathrm{g} / \mathrm{l}]$ & $38.9 \pm 6.2$ & $41.3 \pm 5.7$ & $46.5 \pm 3.7$ & $35.8-50.6[\mathrm{~g} / \mathrm{l}]$ \\
\hline Crosslinks [nmol/pyd/mmol Crea] & $79.0 \pm 11.7 * \#$ & $65.71 \pm 10.2$ & $31.5 \pm 6.2$ & $<50$ \\
\hline Urinary $\mathrm{Ca}[\mathrm{mmol} / 24 \mathrm{~h}]$ & $7.72 \pm 0.75 * \#$ & $4.47 \pm 0.69$ & $1.07 \pm 0.31$ & $<6.2[\mathrm{mmol} / \mathrm{l}]$ \\
\hline
\end{tabular}

Table 3. BMD measurements performed by LUNAR dual-energy X-ray absorptiometry (DEXA) in 80 HIV-1 infected male patients (group I 32 hypogonadal patients; group II 48 eugonadal patients) and 20 mal controls (group III). ( significance between HIV-1 infected men of group I or II and controls $* \mathrm{p}<0.05$ ) (significance between hypogonadal and eugonadal patients \# $\mathrm{p}<$ $0.05)$.

\begin{tabular}{llll}
\hline Parameter & $\begin{array}{l}\text { Group I } \\
(\mathrm{n}=32) \\
\text { HIV-1 Hypogonadism }\end{array}$ & $\begin{array}{l}\text { Group II } \\
(\mathrm{n}=48) \\
\text { HIV-1 Eugonadism }\end{array}$ & $\begin{array}{l}\text { Group III } \\
(\mathrm{n}=20) \\
\text { male controls }\end{array}$ \\
\hline BMD lumbar spine $\left[\mathrm{g} / \mathrm{cm}^{2}\right]$ & $1.018 * \pm 0.031$ & $1.037 \pm 0.024$ & $1.081 \pm 0.026$ \\
BMD Ward`s triangle $\left[\mathrm{g} / \mathrm{cm}^{2}\right]$ & $0.959 \pm 0.052$ & $0.9667 \pm 0.047$ & $1.002 \pm 0.043$ \\
Osteopenia lumbar spine & 13 & 0 & 0 \\
$\begin{array}{l}\text { t-score -1.0 to -2.5 SD below normal] } \\
\text { Osteoporosis Ward's triangle }\end{array}$ & 1 & & 0 \\
[t-score $<2.5$ SD below normal] & & &
\end{tabular}

pooled common group of total HIV-patients or in subjects with determined hypogonadism or eugonadism. Therefore patients were pooled for suitable analysis.

Serum levels of PTH were significantly reduced ( $\mathrm{p}$ $<0.05$ ) in group I compared to the male healthy controls. The serum total calcium was also significantly decreased compared to controls $(p<0.05)$. Serum osteocalcin was significantly decreased in male HIV-1 infected patients of group I ( $p<0.01)$.

The serum levels of $25(\mathrm{OH}) \mathrm{D}$ in HIV-1 infected patients were decreased but did not significantly differ from those of controls. However, the 1,25-dihydroxycholecalciferol 1,25 (OH)2D3 was significantly reduced in both group I and group II.

The excretion rates of crosslinks in the $24 \mathrm{~h} \mathrm{sam-}$ ples of the groups are shown in Table 2. Increased urinary crosslink excretion was also observed in male HIV-1 subjects $(\mathrm{p}<0.05)$ likewise an elevated urinary calcium-excretion $(\mathrm{p}<0.05)$. However, there was an increased crosslink excretion in HIV-1 infected subjects with hypogonadism compared to those patients with normal testicular function $(p<0.05)$. Similary, an elevated urinary excretion of calcium was observed ( $p$ $<0.05)$.
BMD values of the lumbar spine differed significantly between HIV-1 infected patients and controls ( $p$ $<0.05$ ) at all sites measured (Table 3), whereas BMD measurements of the Ward's triangle were not distinct between the two groups of HIV subjects and the controls.

\section{Discussion}

Our study showed significantly lower BMD of the lumbar spine in HIV-1 infected male patients with hypogonadism as compared with BMD values at the spine in control subjects. These findings are in line with the observation that a certain proportion of HIV-patients presents a loss of bone mineral density at the spine, but with normal or near normal BMD values at Ward's triangle. According to prior studies $[10,12,13]$ a decrease in BMD of the lumbar spine is common in HIV-afflicted males. Data on reduced BMD of Ward's triangle or hip are limited. Paton et al. did not find detectable loss of BMD in Hip of 45 HIV-infected patients [10]. However, Fairfield et al. observed reduced BMD both in eugonadal men with acquired immune deficiency related wasting syndrome. Total hip scores were less than -1.0 in $33 \%$ of men 
with wasting syndrome [21]. However, the reduction of BMD at lumbar spine in group 1 of the current patients provides strong evidence that additional hypogonadism has an important influence on individual $\mathrm{BMD}$ in this region. In contrast, osteopenia in Ward's Triangle could not be confirmed in our eugonadal or hypogonadal HIV-1 infected male subjects. It is interesting that hypogonadism is common in AIDS-patients with wasting syndrome [23, 24]. Wasting syndrome has been reported as an independent risk factor for reduction of $\mathrm{BMD}$ both in male and female patients [21, 25]. Therefore, we excluded each patient with weight loss in the recent case history. To date, it is not clear whether our findings translate into a general recommendation for hormone replacement directed only to hypogonadal HIV-1 infected subjects. Over a 12 week treatment period with testosterone eugonadal AIDS patients improved also their BMD at the lumbar spine. On the other hand, the anabolic strategies led to improve muscle mass and BMD [21]. Megestrol acetate treatment resulted in robust weight gain and acrrural of lean body mass in men with HIV-assiciated wasting. Addition of a conventional dose of testosterone preserved sexual functioning but did not significantly increase the proportion of weight gained as lean body mass, suggesting that either Megestrol acetate induced hypogonadism is not a significant determinant of the partitioning of weight gain or higher dose of of testosterone is required to overcome the suppressive effects of Megestrol acetate on testosterone production or action [22]. The contribution of hypogonadism on bone metabolism is linked to the effect of hormone replacement therapy on bone metabolism mediated trough direct osteoblastic and osteoclastic effects [21] or modulation of cytokine milieu, and extraskeletal effects on calcium homeostasis [14, $15]$. We detected a decrease of osteocalcin in hypogonadal patients. Several studies have assessed biochemical marker of bone formation and resorption in patients with $\operatorname{HIV}[7,8,9,26,27]$. Serum osteocalcin were lowered in advanced stages of disease and were positively correlated with CD4 cell counts [8, 9, 19]. Another small study reported a decrease of serum osteocalcin concentration in 16 patients with $\mathrm{HIV}$ as compared to normal controls, particulary with ongoing HIV-1 infection too more than 2 years [29]. A positive correlation between osteocalcin and the number of CD4 cells was described in a male group of 65 HIV-1 infected patients and was independent of existing normal or reduced vitamin 1,25 (OH)2D levels and reduced albumin values and as a marker for severe nutritional protein deficiency [9]. The loss of CD4 cells is associated with reduced bone formation rate [9] and significantly differed between group I and II. Our results in the HIV-1 infected subjects groups were in aggreement with data of male patients recently presented [8, 9, 25, 27]. Additionally, serum levels of propeptide of type I collagen (PICP), a marker of bone formation, were found to be decreased in $13 \mathrm{pa}-$ tients with AIDS as compared with normal controls or patients with HIV-1 infection [26]. It is known, that treatment with recombinant human growth hormone (rhGH) significantly increased PICP levels in normal subjects and in patients with AIDS [26]. In a cross- sectional study, Aukrust et al. [19] evaluated bone markers and inflammatory cytokines in 73 HIV-1 infected patients. As HIV-1 infection advanced, serum levels of osteocalcin decreased and C-telopeptide, a serum marker of bone resorption, increased. Serum levels of soluble TNF $\alpha$ receptor negatively correlated with serum concentrations of osteocalcin and positively with serum levels of C-telopeptide[19]. The notion of increased bone resorption rate in HIV-1 infected patients is underlined by our findings of increased urinary crosslink excretion.

In hypogonadal HIV-infected group we observed a strong dissociation between markers of bone formation and bone resorption. The reasons for these changes in markers of bone remodeling are unclear. Although the activation of direct HIV-mediated effects on osteoblasts and osteoclasts may be involved, it is temping to hypothesize that these findings at least partly reflect activity of TNF $\alpha$ and or other proinflammatory cytokine systems [28]. It has been suggested that therapy inhibiting activation of the transcriptional factor nulcear factor- $\alpha$, a potent inducer of several proinflammatory cytokines, may hold therapeutic potential in the treatment of osteoporosis and other bone disorders [30]. However, findings suggest a resynchronization of bone formation and resorption during the highly-active antiretroviral therapy (HAART) in those patients and support the idea of an interaction between cytokines and bone remodeling $[25,27]$.

Decreased vitamin 1,25 (OH)2D3 levels were found in all of our HIV-infected patients. Haug et al. [30] similary reported reduced $1,25(\mathrm{OH}) 2 \mathrm{D} 3$ and (slightly) reduced $25(\mathrm{OH}) \mathrm{D}$ levels in HIV-1 infected patients with symptomatic AIDS. In comparison with a group of asymptomatic HIV-1 patients, this reduction was statistically significant. Reduced vitamin D levels are in part responsible for an increased bone turnover rate. These findings of reduced $1,25(\mathrm{OH}) 2 \mathrm{D} 3$ are independently of the gonadal function and may be influenced by altered PTH levels. The slightly reduced $25(\mathrm{OH}) \mathrm{D}$ levels in both hypo- and eugonadal subjects can be explained by malnutrition and malabsorption of HIV-1 patients.

Despite low vitamin D levels, the serum PTH values of HIV-1 patients were in the low normal range. This has been corroberated by several studies $[2,8,9$, $31,32,33]$ and was also observed in our first group. In a large study on hypocalcemia in HIV-1 infection, inappropriately low PTH secretion accounted for as many as one-third of cases with hypocalcemia [2].

Hypogonadism is common among HIV-infected men, although the anticipated age-associated reductions were not seen. Furthermore, hepatitis $\mathrm{C}$ infection and other factors, such as injection drug use, were associated with reduced testosterone levels, whereas HIV status was not associated with hypogonadism. Therefore, hypogonadism may be common among older HIV-infected men but is more often associated with comorbid conditions than with HIV infection itself [34]. The first group of our study included four heroin addicts. From this reason the hypogonadism of these (older) patients may be particulary a result from drug abuse. 
Osteopenia and hypogonadism have been associated with antiretroviral therapy particulary with protease inhibitors. However, we here present male patients, which did not receive protease-inhibitors until time of measurement. Nolan et al. found no evidence of accelerated bone loss in patients treated with nelfinavir opr indinavir-containing HAART [33]. Carr et al. present the data of DEXA in $221 \mathrm{HIV}-1$ infected men who were treated with protease inhibitores or reverse transcriptase inhibitors. Osteoporosis was found in $3 \%$ and osteopenia in $44 \%$ of the patients [12]. There was no independent association with other parameters, including type or duration of antiretroviral therapy and lipodystrophy at any site. Reduced BMD was associated with lower weight prior to commencing antiretroviral therapy, whereas low spinal BMD was associated mostly with higher lactate. However, reduction of BMD of male HIV-1infected patients of our study appeared to be stronger. In HIV-infected patients, higher viral load was associated with reduced androgen levels, whereas use of HAART was not [34]. However, a study from Crum-Cianflone et al presents no association between erectile dysfunction or hypogonadism with the current, past, or cumulative use of HIV medications [35].

This study has some limitations, including the measurement of total testosterone without aspect of the free testosterone levels that are considered to be more accurate concerning the link of hypogonadism and bone metabolism. In assessing androgen levels among HIV-infected patients, consideration should be given to measuring levels of free (bioavailable) testosterone, unbound to sex hormone-binding globulin. Increased sex hormone-binding globulin levels among HIV-infected patients may result in relative increases in total testosterone levels that do not reflect bioavaible or free testosterone $[24,37,38]$.

What are the clinical consequences of androgen deficiency in HIV-infected patients? Among HIV-infected men, hypogonadism is associated with reduced muscle mass, decreased strength, and decreased functional status, bone loss and depression [38]. Treatment of hypogonadal HIV-infected men has been shown to increase muscle mass, strength, and quality of life and to improve depression indices and bone mass [37].

Three clinical trials to date have evaluated the use of a bisphosphonate in HIV-infected persons. The trials showed a marked increase in bone mineral density in patients taking alendronate versus those in the control groups Dosing restrictions complicate the use of these agents; diet, exercise, and calcium supplementation remain the foremost recommended strategies to prevent bone loss. The use of estrogen, testosterone, calcitonin, and teriparatide is less studied in HIV-positive patients, but may be considered in select cases [39].

In conclusion, we found a reduction of BMD at the lumbar spine in male HIV-1infected patients. The incidence of osteopenia is elevated in this patient group with even stroner decrease of BMD in patients with hypogonadism. The BMD of Ward's triangle was not affected. A dissociation of bone formation and resorption rate was observed. The loss of bone mineral density also occured in HAART-naive patients. The habitual hypogonadism appears to be of additional relevance for bone metabolism of male HIV-positive patients prior to start of highly active antiretroviral therapy.

\section{REFERENCES}

1. Zaloga GP, and Chernow B: The multifactorial basis for hypocalcemia during sepsis studies of parathyroid hormone-vitamine D axis. Ann Int Med 1987; 107: 36-41.

2. Kuehn EW, Anders HJ, Bogner JR, Obermaier J, Goebel FD, Schlöndorff D: Hypocalcaemia in HIV-infection and AIDS. J Intern Med 1999; 245: 69-73.

3. Dluhy RG: The growing spectrum of HIV-releated endocrine abnormalities J Clin Endocrinol Metab 1990; 70: 563-565.

4. Glass AR, and Eil C: Ketoconazole-induced reduction in serum 1,25-dihydroxy-vitamin $\mathrm{D}$, total serum calcium in hypercalcemic patients. J Clin Endocrinol Metab 1988; 66: 934-938.

5. Jacobs MB: The aquired immune deficiency syndrome and hypercalcemia. West J Med 1986; 114: 467-471.

6. Pont A: Unusual causes of hypercalcemia. Endocrinol Metabol Clin North Am 1989; 18: 753-764.

7. Hernandez Quero J, Centeno NO, Munoz-Torres M, Martinez-Perez A, and Higuera Torres-Puchol J M: Alterations in bone turnover in HIV-positive patients Infection; 1993, 21: 220-222.

8. Serrano M, Marinoso JC, Soriano JC, Rubies-Prat J, Aubia J. Coll, J., Bosch J, Del Rio 1, Vila J, Goday A, and Nacher M: Bone remodeling in human immunodeficiency virus-1-1infected patients. A histomorphometric Study. Bone 1995; 16: 185-191.

9. Teichmann J, Stephan E, Discher T, Lange U, Federlin K, Stracke H, Friese G, Lohmeyer J, Bretzel RG: Changes in calciotropic hormones and biochemical markers of bone metabolism in patients with human immunodeficiency virus infection. Metabolism 2000; 49: 1134-1139.

10. Paton NIJ, Macallan DC, Griffin GE, Pazianas M: Bone mineral density in patients with human immunodeficiency virus infection. Calcif Tissue Int 1997; 61: 30-32.

11. Tebas P, Powderly WG, Claxton S, Marin D, Tantisriwat T, Teitelbaum SL, Yarasheski KE: Accelerated bone and mineral loss in HIV-infected patients receiving potent antiretroviral therapy. AIDS; 2000, 14: 63-67.

12. Carr A, Miller J, Eisman JA, Cooper DA: Osteopenia in HIV-infected men: association with asymptomatic lactic acidemia and lower weight pre-antiretroviral therapy. AIDS 2001; 15: 703-709.

13. Moore AL, Vashisht A, Sabin CA, Mocroft A, Madge S, Phillips AN, Studd JW, Johnson MA. Reduced bone mineral density in HIV-positive individuals AIDS 2001; 15:1731-1733.

14. Manalogas SC, Jilka RL Bone marrow, cytokines, and bone remodelling. Emerging insights into pathophysiology of osteoporosis. N Engl J Med 1995; 332: 529-534.

15. Orwoll ES, Klein RF. Osteoporosis in men Endocrin Rev 1995; 16: 87-116

16. Horowitz MC Cytokines and estrogen in bone: Antiosteoporotic effects. Science 1993; 260: 626-627.

17. Dobbs AS, Demsey MA, Ladenson PW, Polk BF, Endocrine disorders in men infected with human immunodeficiency virus Am J Med 1988; 84: 611-616.

18. Youle MS: Severe hypocalcemia in AIDS patients treated with foscarnet and pentamidine. Lancet 1988; 331: 14551456.

19. Jacobson MA, Gambertoglio JG, Aweeka FT, Causey DM, Portale AA: Foscarnet-induced hypocalcemia and effects of foscarnet on calcium metabolism. J Clin Endocrinol Metab 1991; 72: 1130-1135. 
20. Bühl A, and Zöfel P. SPSS für Windows Version 6. Addison-Wesley; 1994.

21. Fairfield WP, Finkelstein JS, Klibanski A, Grinspon SK. Osteopenia in eugonadal men with acquired immunodeficiency syndrome wasting syndrome. J Clin Endocrinol Metab 2001; 86: 2020-2026.

22. Mulligan K, Zackin R, Von Roenn JH, Chesney MA, Egorin MJ, Sattler FR, Benson CA, Liu T, Umbleja T, Shriver S, Auchus RJ, Schambelan M: Testosterone supplementation of megestrol therapy $\mathrm{d}$ oes not enhance lean tissue accrual in men with human immunodeficiency virus-associated weight loss: a randomized, double-blind, placebo-controlled, multicenter trial. J Clin Endocrinol Metab 2007; 92: 563-70.

23. Rietschel P, Corcoran C, Stanlay T, Basgoz N, Klibanski A, Grinspoon SK. Prevalence of hypogonadism among men with weight loss related to human immunodeficiency virus infection who were received highly active antiretroviral therapy. Clin Infect Dis 2000; 31:1240-1244.

24. Mylonakis E, Koutkia P, Grinspoon SK. Diagnosis and treatment of androgen-deficiency in human immunodeficiency virus-infected men and women. Clin Infect Dis 2001; 15: 857-864.

25. Huang JS, Wilkie SJ, Sullivan MP, Grinspoon S: Reduced bone density in androgen-deficient women with acquired immune deficiency syndrome wasting. J Endocrinol Metab 2001; 86: 3533-3539.

26. McNurlan MA, Garlick PJ, Frost RA, Decristofaro KA, Lang CH, Steigbigel RT, Fuhrer J, Gelato M: Albumin synthesis and bone kollagen formation in human immunodeficiency virus-positive subjects. Differential effects of growth hormone administration. J Clin Endocrinol Metab 1999; 83: 3050-3055.

27. Aukrust P, Haug Cj, Ueland T, Lien E, Müller F, Espevik T, Bollerslev J, Froland SS: Decreased bone formative and enhanced resorptive markers in human immunodeficiency virus infection: Inivation of normalization of the bone-remodeling process during highly active antiretroviral therapy. J Clin Endocrinol Metab 1999; 84: 145-150.

28. Aukrust P, Liabakk NB, Müller F, Lien E, EspevikT, Froland SS: Serum levels of tumor necrosis factor (TNF $\alpha)$ and soluble TNF receptors in human immunodeficiency virus type 1-infection -correlations to clinical, immunologic, and virologic parameters. J Infect Dis 1994; 169: 420-424.

29. Hofbauer LC, Khosla S, Dunstan CR, Lacey DL, Boyle WJ, Riggs BL: The roles of osteoprotegerin and osteoprotegerin ligand in the paracrine regulation of bone resorption. J Bone Miner Res 2000; 15: 2-12.

30. Haug C, Müller F, Aukrust P et al: Subnormal serum concentration of 1,25-vitamin D in human immunodeficiency virus infection: Correlation with the degree of immunedeficiency and survival. J Infect Dis 1994; 169: 889-893.
31. Jaeger Ph, Otto St, Speck RF, Villiger L, Horber FF, Casez JP, and Takkinen R. Altered parathyroid gland function in severely immunocompromised patients infected with human immunodeficiency virus. J Clin Endocrinol Metab 1994; 79: 1701-1705.

32. Pedrazzoni Vescovi PP, Maninetti L, Michelini M, Zaniboni G, Pioli G, Costi D,Alfano FS, and Passeri M. Effects of chronic heroin abuse on bone and mineral metabolism. Acta endocrinol 1993; 93: 42-44.

33. Nolan D, Upton R, McKinnon E, John M, James I, Adler B, Roff G, Vasikaran S, Mallal S: Stable or increasing bone mineral density in HIV-infected patients treated with nelfinavir or indinavir. AIDS 2001; 15: 1275-1280.

34. Klein R, LoY, Santoro N, Dobs A: Androgen levels in older men who have or who are at risk of acquiring HIV infection. Clin Infect Dis 2005; 41:57-66.

35. Crum-Cianflone NF, Bavaro M, Hale B, Amling C, Truett A, Brandt C, Pope B, Furtek K, Medina S, Wallace MR: Erectile dysfunction and hypogonadism among men with HIV. AIDS Patient Care STDS 2007; 21:9-19.

36. Mondy K, Yarashekski K, Powderly WG, Whyte M, Claxton S, DeMarco D, Hoffmann M, Tebas P: Longitudinal evaliation of bone mineral density and bone markers in human imunodeficiency virus infected individuals. Clin Infect Dis 2003; 36: 482-490.

37. Bhasin S, Cunningham GR, Haves FJ, Matsumoto AM, Snyder PJ, Swerdloff RS, Montori VM: Testosterone therapy in adult men with androgen deficiency syndromes: an endocrine society clinical practice guideline. J Clin Endocrinol Metab 2006; 91:1995-2010.

38. Grinspoon S: Androgen deficiency and HIV Infection. Clinical Infect Diseases 2005; 41: 1804-5.

39. Clay PG, Voss LE, Williams C, Daume EC: Valid treatment options for osteoporosis and osteopenia in HIV-infected persons. Ann Pharmacotherap 2008; 42:670-9.

Received: September 14, 2008 / Accepted: January 9, 2009

Address for correspondence:

PD Dr.med. Joachim Teichmann

Innere Medizin - Gastroenterologie und

Endokrinologie-Diabetologie

St. Josefskrankenhaus Heidelberg

Landhausstraße 25

69115 Heidelberg

Germany

Tel.: $\quad+49-6221 / 526-880$

E-mail: J.Teichmann@st.josefskrankenhaus.de 